\title{
Recent advances on supply chain management
}

\author{
Mohammad Reza Ghaeli ${ }^{\mathbf{a}^{*}}$
}

${ }^{a}$ School of Management, New York Institute of Technology, 1700 - 701 W Georgia St.,Vancouver, BC V7Y 1 K8 Canada

\begin{tabular}{l}
\hline C H R O N I C L E \\
\hline Article history: \\
Received: October 1, 2017 \\
Received in revised format: No- \\
vember 16, 2017 \\
Accepted: May 17, 2018 \\
Available online: \\
May 17, 2018 \\
\hline Keywords: \\
Supply chain management \\
Logistics \\
Canada
\end{tabular}

\section{A B S T R A C T}

\begin{abstract}
Supply chain management (SCM) is the active centralize of a business' supply related activities to increase customer value and enhance a competitive advantage in the marketplace. SCM includes various efforts by suppliers to implement and effective supply chains which are as economical as possible. Supply chain includes several issues from production, to product development, to the information systems required to direct these undertakings. This paper presents recent advances of supply chain management and issues related in Canadian industries. According to our survey, trust is an important part of the supply chain and business partners. The study also discusses different challenges for the implementation of SCM in Canadian small and medium enterprises.
\end{abstract}

C 2017 by the authors; licensee Growing Science, Canada

\section{Introduction}

In business, supply chain management (SCM), the management of the flow of goods and services, engages the shipment and storage of raw materials, work-in-process inventory, and finished products and services from an origin to a destination. Interconnected or interlinked networks, channels and node businesses are integrated in the provision of products or services needed by end customers in a supply chain (SM) (Harland, 1996). According to Chopra and Meindl (2007), supply-chain management has been defined as "design, planning, execution, control, and monitoring of supply chain activities with the objective of creating net value, building a competitive infrastructure, leveraging worldwide logistics, synchronizing supply with demand and measuring performance globally". SCM practices comes significantly from the areas of industrial engineering, systems engineering, operations management, logistics, procurement, information technology, and marketing and attempts to reach a comprehensive method to reach the minimum expenses. Marketing channels play essential role in SCM and studies on SCM have concentrated on topics associated with sustainability and risk management, etc. SCM activities need to be included as part of firms' strategic decisions (Crossan \& Berdrow, 2003). Fig. 1 demonstrates a sample components of the supply chain management.

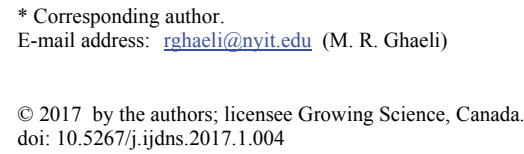




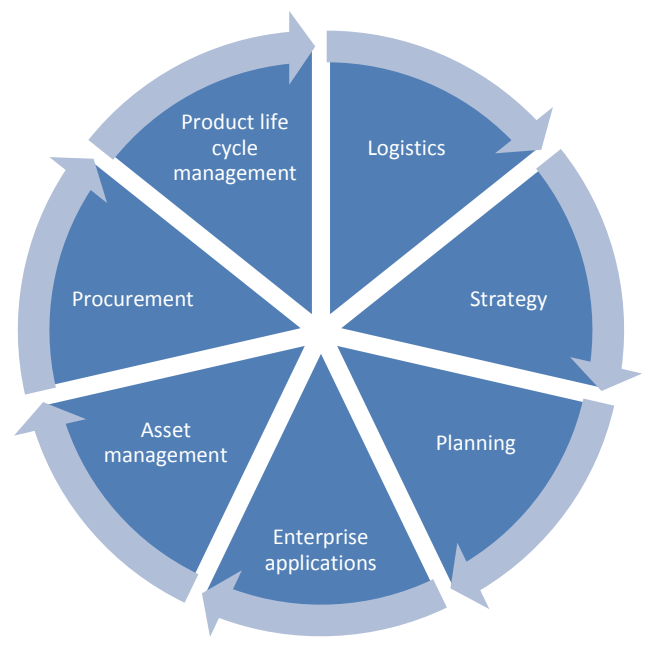

Fig. 1. Supply chain management

\section{Supply chain management and analytical capabilities}

Trkman et al. (2010) studied the relationship between analytical capabilities in the plan, source, make and deliver area of the SC and its performance based on information system support and business process orientation as moderators based on a survey questionnaire in different countries including USA and Canada. The results recommend the availability of a statistically substantial association between analytical capabilities and performance. Awaysheh and Klassen (2010) tried to determine the integration of social issues in the SCM in terms of the operations management perspective. Moreover, they tried to develop a set of scales to consider multiple aspects of supplier socially responsible practices. They also investigated the relative effect of three dimensions of SC structure, namely transparency, dependency and distance, for the integration of these socially responsible issues. They validated multi-item scales for each of the four dimensions of supplier socially responsible practices through supplier human rights and supplier labour practices. Increased transparency, as stated in bigger product visibility by the end-consumer in their survey was associated with increased implementation of supplier human rights, which could assist us to help a firm's brands. Organizational distance, in their survey, as considered by the total length of the supply chain was associated with increased use of multiple supplier socially responsible practices. Cannon et al. (2010) studied buyer-supplier relationships in international markets in Canada and reported that buyer-supplier relationships could be beneficial when SC partners to the relationship provide a long-term orientation. They reported that a buyer's trust of a supplier and the supplier's performance could significantly influence on the buyer's long-term orientation towards the relationship. They also suggested that the relative effects of trust and performance on long-term orientation could be also moderated by culture.

\section{Supply chain integrations}

During the past two decades, competition in the manufacturing sector has edged up as globalization and customers' needs have emerged. Thus, many organizations are battling not only based on their internal abilities but also based on their capabilities to increase power in the supply chain. Many studies recommend that strategic alignment in SC, evaluated by the degree of fitting between supply management and market needs, is essential for the success of all enterprises in the global marketplace. Vachon et al. (2010) examined the possible relationship between SC strategic alignment based on the traditional competitive priorities and the kind of interactions with suppliers. Their practical analysis implemented data from 512 manufacturing companies in Canada from 2003 to 2005. They reported that interactions with suppliers that are increasingly based on cooperation had relationship with a better alignment of competitive priorities which are the characteristics of the supply chains. 


\section{Sustainable supply chain management}

There is a steady growing structure of studies on the theory and practice of sustainable SCM (SSCM). Nevertheless, few studies have been accomplished on the extent to which firms have integrated sustainability principles into the management of their SC and the evaluation of supplier performance. Morali and Searcy (2013) performed a comprehensive review of sustainable SCM practices in Canada. They tried to explore the extent to which corporate sustainability principles could be integrated into SCM in corporations. The study performed a content analysis of 100 Canadian corporate sustainable development reports and in-depth interviews with 18 Canadian experts on SSCM and reported the wide array of ways in which Canadian corporations investigate SSCM problems. Amongst other topics, subjects related to SC governance, standards for SSCM, collaboration with suppliers, performance measurement, and accountability within the supply chain were also explored. They reported that there were several challenges in reaching sustainability into SCM. These issues highlighted the possible future directions for research in SSCM. Cambero and Sowlati (2016) provided social benefits in multiobjective optimization of forest-based bioenergy and biofuel supply chains. They illustrated the implementation of their model through a case study in the interior region of British Columbia, Canada where various utilization paths for available forest and wood residues were studied.

\section{Barriers of implementation of SCM in small and medium enterprises}

Archer et al. (2008) detected the perceived importance of barriers in the small and medium enterprises (SMEs) for the adaptation of internet business procurement and SC solutions. They performed a telephone survey of a sample of 173 Canadian SMEs, stratified by size of company and based on the type of business, i.e. distributors, retailers or manufacturers. The data were studied statistically through an analysis of variance approach and reported a relationship between SME internet adopters and nonadopters. There was a requirement for education for all SME management on the advantages and challenges on applying e-business solutions. Inter-organizational data which could be needed to link SC partners could be a major barrier to online solutions. There was also a substantial dependency among SC partners in decisions on adopting online links. Flexibility, agility and ability of SMEs definitely help them to implement partial e-business solutions for low volumes of business, but this method could be ineffective when transaction volumes increases dramatically.

SCM also provides substantial opportunities to reduce a company's environmental unwanted effects. Cote et al. (2008) investigated the supply chains of three SMEs operating in the Burnside Industrial Park in Nova Scotia, Canada to determine the opportunities to help environmental performance of SMEs linked in supply chains. The study reported that time and, to a lesser degree, financial resources to address solid waste and energy issues were the biggest limiting factors. Small suppliers, and even to a certain degree medium-sized enterprises, faced challenges in assigning resources to initiatives which were not viewed as directly related to their core function, namely manufacturing the product or providing the service. This study clearly indicated that opportunities would be available to reduce greenhouse gas emissions and solid waste. Nevertheless, the advantage which could be obtained from the use of any of the individual actions in the supply chains explored in this study were individually small.

\subsection{Trust in supply chain management}

Trust is an important parameter on building commitment among SC partners. The presence of trust helps measurably the chance of successful SC performance. The lack of trust among SC partners normally results in ineffective performance as the transaction costs. Nevertheless, the literature often indicates an association between trust and commitment. Chen et al. (2011) studied the role of information sharing, information quality, and information availability in the development of trust and commitment in SC relationships using some data which were collected from Taiwan and Canada based 
on a field questionnaire. They reported that there was a positive relationship between the level of quality, and availability, and the level of trust; information sharing and commitment.

\section{Conclusion}

Supply chain management plays essential role for the improvement of business activities and increasing firms' productivity. This paper has presented a brief review on different issues associated with supply chain management in Canada. The study has revealed that trust is an important part of SC and business partners have to build a mutual trust in supply chain. The study has also discussed different challenges for the implementation of SCM in Canadian small and medium enterprises. The study has also reported some evidences that a good SCM implementation could contribute to reach sustainable economy.

\section{References}

Archer, N., Wang, S., \& Kang, C. (2008). Barriers to the adoption of online supply chain solutions in small and medium enterprises. Supply Chain Management: An International Journal, 13(1), 73-82.

Awaysheh, A., \& Klassen, R. D. (2010). The impact of supply chain structure on the use of supplier socially responsible practices. International Journal of Operations \& Production Management, 30(12), 1246-1268.

Cambero, C., \& Sowlati, T. (2016). Incorporating social benefits in multi-objective optimization of forest-based bioenergy and biofuel supply chains. Applied Energy, 178, 721-735.

Cannon, J. P., Doney, P. M., Mullen, M. R., \& Petersen, K. J. (2010). Building long-term orientation in buyer-supplier relationships: The moderating role of culture. Journal of Operations Management, 28(6), 506-521.

Chen, J. V., Yen, D. C., Rajkumar, T. M., \& Tomochko, N. A. (2011). The antecedent factors on trust and commitment in supply chain relationships. Computer Standards \& Interfaces, 33(3), 262-270.

Chopra, S., \& Meindl, P. (2007). Supply chain management. Strategy, planning \& operation. In Das summa summarum des management (pp. 265-275). Gabler.

Cote, R. P., Lopez, J., Marche, S., Perron, G. M., \& Wright, R. (2008). Influences, practices and opportunities for environmental supply chain management in Nova Scotia SMEs. Journal of Cleaner Production, 16(15), 1561-1570.

Crossan, M. M., \& Berdrow, I. (2003). Organizational learning and strategic renewal. Strategic management journal, 24(11), 1087-1105.

Harland, C. M. (1996). Supply chain management, purchasing and supply management, logistics, vertical integration, materials management and supply chain dynamics. Blackwell Encyclopedic Dictionary of Operations Management. UK: Blackwell, 15.

Morali, O., \& Searcy, C. (2013). A review of sustainable supply chain management practices in Canada. Journal of Business Ethics, 117(3), 635-658.

Trkman, P., McCormack, K., De Oliveira, M. P. V., \& Ladeira, M. B. (2010). The impact of business analytics on supply chain performance. Decision Support Systems, 49(3), 318-327.

Vachon, S., Halley, A., \& Beaulieu, M. (2009). Aligning competitive priorities in the supply chain: the role of interactions with suppliers. International Journal of Operations \& Production Management, 29(4), 322-340.

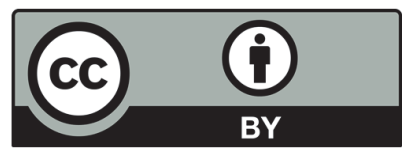

(C) 2017 by the authors; licensee Growing Science, Canada. This is an open access article distributed under the terms and conditions of the Creative Commons Attribution (CC-BY) license (http://creativecommons.org/licenses/by/4.0/). 